\title{
Defect Engineering of ZnO Nanoparticles for Bio-imaging Applications
}

\author{
Josh E. Eixenberger ${ }^{\dagger} \neq$, Catherine B. Anders ${ }^{\Delta}$, Katelyn Wada ${ }^{\ddagger}$, Kongara M. Reddy $^{\ddagger}$, Raquel \\ J. Brown $^{\perp}$, Jonathan Moreno-Ramirez ${ }^{\ddagger}, \S$, Ariel E. Weltner ${ }^{\Phi}$, Chinnathambi Karthik ${ }^{\phi}$, Dmitri \\ A. Tenne ${ }^{\ddagger}$, Daniel Fologea ${ }^{\ddagger}$, Denise G. Wingett ${ }^{\dagger},{ }^{*}$ \\ †Biomolecular Sciences Graduate Programs, Boise State University, 1910 University Dr., Boise, \\ ID 83725, USA \\ ‡Department of Physics, Boise State University, 1910 University Dr., Boise, ID 83725, USA \\ ${ }^{\perp}$ Biomolecular Research Center, Boise State University, 1910 University Dr., Boise, ID 83725, \\ USA \\ ${ }^{\oplus}$ Micron School of Material Science and Engineering, Boise State University, 1910 University Dr., \\ Boise, ID 83725, USA \\ ${ }^{\Delta}$ Idaho Veterans Research \& Education Foundation - Boise VA Medical Center, 500 W Fort St, \\ Boise, ID 83702, USA \\ §Riverstone International School, 5521 E Warm Springs Ave., Boise, ID 83716, USA
}

\begin{abstract}
Many promising attributes of $\mathrm{ZnO}$ nanoparticles $(\mathrm{nZnO})$ have led to their utilization in numerous electronic devices and biomedical technologies. $\mathrm{nZnO}$ fabrication methods can create a variety of intrinsic defects that modulate the properties of $\mathrm{nZnO}$, which can be exploited for various purposes. Here we developed a new synthesis procedure that controls certain defects in pure $\mathrm{nZnO}$ that are theorized to contribute to the n-type conductivity of the material. Interestingly, this procedure created defects that reduced the nanoparticle band gap to $\sim 3.1 \mathrm{eV}$ and generated strong emissions in the violet to blue region while minimizing the defects responsible for the more commonly observed broad green emissions. Several characterization techniques including TGA, FT-IR, XPS, TEM, Raman, photoluminescence and ICP-MS were employed to verify the sample purity, assess how modifications in the synthesis procedure affect the various defects states and understand how these alterations impact the physical properties. Since the band gap significantly decreased and a relatively narrow visible emissions band were created by these defects, we investigated utilizing these new $\mathrm{nZnO}$ for bio-imaging applications using traditional fluorescent
\end{abstract}

\footnotetext{
*Corresponding Author Denise Wingett, Boise State University, 1910 W. University Dr., Boise, ID 83725. Fax: 208-392-1430. Phone number: 208-426-2921. denisewingett@ boisestate.edu.

Author Contributions

The manuscript was written through contributions of all authors. All authors have given approval to the final version of the manuscript. ASSOCIATED CONTENT

Supporting Information. XRD patterns and TEM images of the $\mathrm{nZnO}$ before and after annealing, DLS size distribution, XPS scans of the $\mathrm{nZnO}$ post annealing, energy level diagram for the $\mathrm{nZnO}$, high magnification confocal images of the new $\mathrm{nZnO}$, a table of ICPMS results, absorbance and emission spectra for quinine sulfate/nZnO, table of results for quantum yield determination, and caption for the associated NP-time series video.
} 
microscopy techniques. Whereas most $\mathrm{nZnO}$ generally require $\mathrm{UV}$ excitation sources to produce emissions, we demonstrate that reducing the band gap allows for a $405 \mathrm{~nm}$ laser to sufficiently excite the nanoparticles to detect their emissions during live-cell imaging experiments using a confocal microscope. This work lays the foundation for the use of these new $\mathrm{nZnO}$ in various bioimaging applications and enables researcher to investigate the interactions of pure $\mathrm{nZnO}$ with cells through fluorescence-based imaging techniques.

\section{Graphical Abstract}

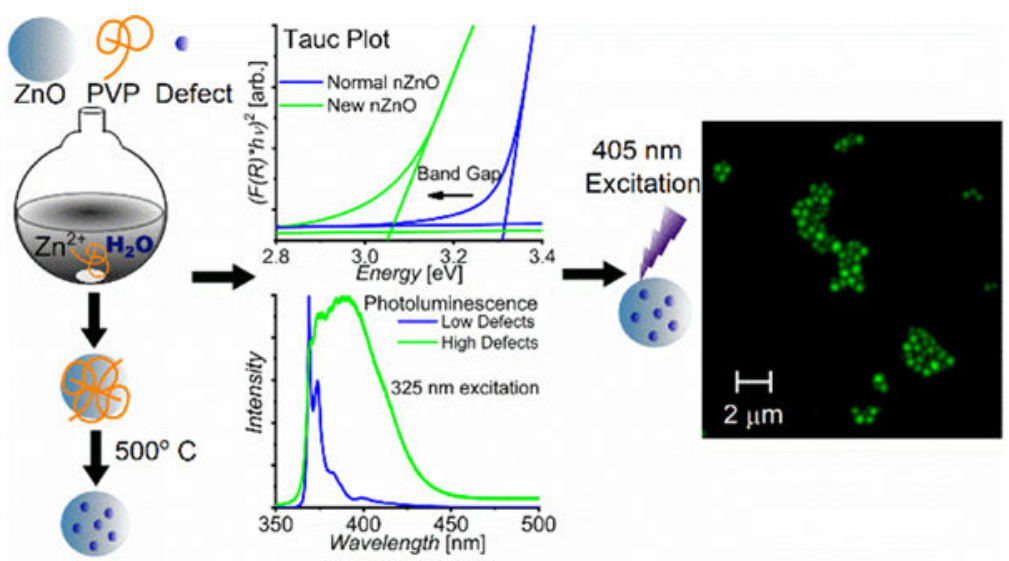

\section{Keywords}

ZnO Nanoparticles; Bio-imaging; Defects; Fluorescence; Photoluminescence; Raman; Cancer; Toxicity

\section{INTRODUCTION}

Nanomaterials composed of $\mathrm{ZnO}$ are highly produced and extensively studied due to their promising attributes in numerous fields. $\mathrm{ZnO}$ nanomaterials (NMs) are considered for various potential cancer treatment options, water treatment applications and electronic devices. ${ }^{1-3}$ The flexible nature of NMs, specifically the ability to control physical properties such as size, surface chemistry, catalytic activity and defect structure, makes them suitable for many novel devices. Researchers often focus on how these properties relate to $\mathrm{ZnO}$ nanoparticle $(\mathrm{nZnO})$ toxicity; especially as they appear to be selectively toxic towards cancer cells when compared to their normal non-transformed counter-parts. ${ }^{4}$ Although there has been a wealth of data collected about $\mathrm{nZnO}$ properties and toxicity, the mechanism of toxicity and cell selectivity remains controversial as it is not fully understood. The ability to fluorescently track $\mathrm{nZnO}$ within biological systems is an avenue that should be further explored as it would likely facilitate a better understanding of $\mathrm{nZnO}$ interactions with various cell types and cancer.

Numerous semiconducting nanoparticles (NPs) have generated great interest as biological labels due to their small size, photo-stability and relatively long fluorescence lifetimes. .56 The most traditional systems use cadmium chalcogenides as their emission is tunable 
through size modulation and generally have narrow emission spectra. Unfortunately these particles are toxic towards biological systems through the release of $\mathrm{Cd}^{2+}$ ions; reportedly highly toxic in the nanomolar range. ${ }^{7}$ In contrast, $\mathrm{nZnO}$ display relatively low toxicity, at an even higher micro-to-millimolar range. ${ }^{8,9}$ As $\mathrm{nZnO}$ are comparatively less toxic, their potential use in bio-imaging has received considerable attention and yet only modest progress has been made to date.

Using $\mathrm{nZnO}$ as a biological labelling tool is limited by the need to use UV excitation sources coupled with corresponding emission spectra of $\mathrm{nZnO}$ that is generally in the UV range (correlating to near band emissions of $\sim 3.37 \mathrm{eV}$ or $\sim 368 \mathrm{~nm}$ ) and commonly a broad green emission ( 500-700 nm). True UV excitation sources $(100 \mathrm{~nm}-380 \mathrm{~nm})$ are generally absent in conventional fluorescence imaging instruments with most traditional fluorescence microscopy techniques using excitation wavelengths of $405 \mathrm{~nm}$ or longer, which is insufficient to excite $\mathrm{nZnO}$ as it is below the band gap energy of $\mathrm{ZnO}$. Monitoring UV emissions with standard fluorescent imaging equipment is often not possible and UV light has a relatively low tissue depth penetration, which limits the ability to study $\mathrm{nZnO}$ in biological systems. Additionally, the broad green emission of $\mathrm{nZnO}$ is theorized to originate from surface defects, such as oxygen vacancies, that can be quickly quenched by transformations in solution such as hydroxide formations and conversion to zinc carbonate/ phosphate species. ${ }^{10-12}$ An additional complication to targeting the broad green emission region for fluorescence microscopy techniques is that emissions in this region of the spectrum is broad enough to overlap with fluorophores commonly used in cell/tissue research and the autofluorescence generated by various biological structures. Therefore, targeting the broad green emission spectra of $\mathrm{nZnO}$ for imaging purposes may not be suitable for many applications.

Some of the aforementioned drawbacks have been overcome through modifications of $\mathrm{nZnO}$, creating novel fluorescent particles through methods such as encapsulating dyes including fluorescein isothiocyanate (FITC), coating nanoparticles (NPs) with polymers, and doping elements into $\mathrm{nZnO}$ to modulate the band gap. ${ }^{13-16}$ However, these modifications may impact other properties of $\mathrm{nZnO}$, potentially altering their toxicity mechanism and making them unsuitable for specific types of studies. While these avenues may shed some light into understanding the interplay of $\mathrm{nZnO}$ with various cell types, conclusions drawn from these approaches do not necessarily reflect how unmodified $\mathrm{nZnO}$ interacts with cells.

In addition to biological applications, $\mathrm{nZnO}$ are well suited for optoelectronic devices. Modulating the absorbance, emission spectra and charge carriers in $\mathrm{nZnO}$ has been a goal for optoelectronic device applications. To these ends, one approach has been to dope various elements in the crystal lattice of $\mathrm{ZnO},{ }^{17}, 18$ while other researchers have sought to improve $\mathrm{ZnO}$ performance by producing highly oriented and defect-free $\mathrm{ZnO}$ nanomaterials.

Producing $\mathrm{ZnO}$ materials free of defects is hard to achieve, especially at the nanoscale; some have focused their investigations on ways to reduce the defects produced when synthesizing $\mathrm{nZnO}$, while others have actively pursued ways to utilize the various defects states that are inherent to $\mathrm{ZnO}$. 
Control of $\mathrm{ZnO}$ NM defect states is achieved through various means such as growth on substrates, annealing in various atmospheric conditions and via numerous deposition techniques. ${ }^{19-22}$ For $\mathrm{nZnO}$ specifically, achieving control of various defects in wet chemical methods can be challenging. Many reports have focused on the green luminescent broad band produced through differing methods and often attribute this emission to oxygen related defects, but the precise defect states or surface species responsible are still controversial, making precise control difficult due to lack of a known mechanism. ${ }^{23-25}$

In this report, we pursued controlling defects of highly pure $\mathrm{nZnO}$ that affect the emission spectra in the violet to blue region, theoretically creating shallow donors such as zinc interstitials. By controlling these defects, the emission spectra were red-shifted and broadened, creating strong emissions up to $\sim 430 \mathrm{~nm}$. Additionally, the optical band gap was shifted down to $\sim 3.1 \mathrm{eV}$ allowing excitation sources, such as a $405 \mathrm{~nm}$ laser used in confocal microscopy, to produce sufficient emissions to image the particles without any other modifications. Through variations in the wet chemical synthesis procedure, we demonstrate that the described defect states can be systematically controlled. To our knowledge, this is the first report to demonstrate the ability to fluorescently image pure nZnO using a $405 \mathrm{~nm}$ excitation source due to defects altering the physical properties of the $\mathrm{nZnO}$ without any further modifications to the material.

\section{MATERIALS AND METHODS}

\section{ZnO Nanoparticle Synthesis}

The new synthesis procedure for producing $\mathrm{nZnO}$ was adapted from previous procedures with various modifications. ${ }^{26}$ Zinc acetate dihydrate was used as the zinc source and diethylene glycol (DEG) as the solvent. To control the defects in the wet chemical synthesis, three parameters were varied; the amount of polyvinylpyrrolidone (PVP), water, and annealing temperature. The solution was created first by the simultaneous addition of PVP (molecular weight 58k) and zinc acetate, followed by the addition of DEG and initially heated to $80^{\circ} \mathrm{C}$. Various amounts of water were then added, the temperature brought up to $150^{\circ} \mathrm{C}$, and then held for 75 minutes. Once the solution cooled to room temperature, the samples were centrifuged at $41,410 \mathrm{X} \mathrm{g}$ to remove the DEG and subsequently washed with absolute ethanol. The pellet was dried overnight at $60^{\circ} \mathrm{C}$ and then annealed in air at the various temperatures indicated.

Characterization.-The $\mathrm{nZnO}$ samples were characterized using several techniques. Xray diffraction (XRD) spectra were collected using a Rigaku Miniflex 600 X-ray diffractometer and used to determine the crystal phase, lattice parameters and to estimate the average crystal size using Rigaku PDXL software version 1.8.0.3. Thermal gravimetric analysis (TGA) was performed using a Netzsch STA449F1 TGA-DSC in order to define the ideal temperature and time to remove retained chemical species from the synthesis procedure. Transmission electron microscopy (TEM) was utilized to obtain both average crystal size distributions and determine the NP morphology using a JEOL JEM-2100 HR analytical transmission electron microscope. To obtain atomic concentrations and evaluate sample purity, both X-ray photoelectron spectroscopy (XPS) and Fourier transform infrared 
spectroscopy (FTIR) were utilized. A Physical Electronics Versaprobe system with a monochromated $\mathrm{Al} \mathrm{K}_{\mathrm{a}} \mathrm{X}$-ray source was used to obtain the XPS spectra and a Bruker Tensor 27 spectrometer was used for FTIR spectra collection. FTIR pellets were prepared by grinding $1.5 \mathrm{mg}$ of the NP sample with $0.200 \mathrm{~g}$ of spectroscopic grade $\mathrm{KBr}$ and subsequently pressed for 4 minutes with 8 tons of pressure. A Malvern Zetasizer NanoZS was used to collect dynamic light scattering (DLS) measurements by using a concentration of $\mathrm{ZnO}$ NPs of $0.5 \mathrm{mg} / \mathrm{mL}$ in nanopure water. For inductively coupled plasma mass spectrometry (ICP-MS) experiments, the $\mathrm{nZnO}$ were dissolved in $25 \mathrm{~mL}$ of highly pure $2 \%$ nitric acid solution and analyzed by a Thermo-electron X-series II quadrupole ICP-MS. The samples were analyzed for various metal contaminations such as iron, cobalt and nickel against the total zinc content. For Raman and photoluminescence (PL) experiments, the $\mathrm{nZnO}$ were mounted onto a silicon oxide wafer and the spectra were measured in backscattering geometry using a Jobin Yvon T64000 0.64m triple spectrometer equipped with a liquid nitrogen cooled multichannel CCD detector. Spectra were recorded at $10 \mathrm{~K}$ using a variable temperature closed cycle helium cryostat. Ultraviolet light (325 nm line of $\mathrm{He}-\mathrm{Cd}$ laser) was used for excitation.

ZnO Nanoparticle and Live Cell Imaging.-Confocal microscopy was utilized to image both the $\mathrm{nZnO}$ and T47D cells treated with $\mathrm{nZnO}$. Because this new method of $\mathrm{nZnO}$ synthesis achieves a lower band gap of $\sim 3.1 \mathrm{eV}$, a $405 \mathrm{~nm}$ laser was able to be used as an excitation source and $\mathrm{nZnO}$ fluorescence monitored.

For live cell imaging experiments, T47D (ATCC HTB-133), a cell line derived from ductal breast carcinoma (ATCC; Manassas, VA) was maintained in log phase and cultured in RPMI 1640 media following ATCC recommendations. Prior to imaging experiments, the cells were washed and resuspended in a custom made RPMI 1640 media free of HEPES, phenol red and phosphate (PPH free RPMI 1640; Thermo Fisher Scientific; Grand Island, NY) to prevent increased NP dissolution, remove fluorescent background signal and reduce the chemical transformation of the NPs, respectively. ${ }^{10,27}$ The cells were then transferred to Nunc Lab-Tek II Chambered cell culture slides (ThermoFisher; Waltham, MA). Following an overnight incubation to ensure cell adhesion, $\mathrm{nZnO}$ were added at a final concentration of $30 \mu \mathrm{g} / \mathrm{mL}$ and further incubated to allow for $\mathrm{nZnO}$-cell interactions. Control (nZnO-free) cells were cultured in the same manner to assess auto-fluorescence generated using the 405 $\mathrm{nm}$ laser to excite the $\mathrm{nZnO}$. Prior to imaging, live cells were stained with the plasma membrane stain Cell Mask Orange (Invitrogen; Carlsbad, CA). In brief, stain was added to culture media for at a final concentration of $5 \mu \mathrm{g} / \mathrm{ml}$. All confocal images were acquired with a Zeiss 510 LSM system with the Zeiss Axiovert Observer Z1 inverted microscope and ZEN 2009 Imaging software (Carl Zeiss, Inc.; Thornwood, NY) utilizing Diode (405 nm) and $\mathrm{HeNe}$ (543) lasers as excitation sources; a Plan-Apochromat 20x/NA 0.8, Fluar 40x/NA 1.3 oil, or a-Plan Fluar 100x/NA 1.44 oil objective; and band-pass BP filters of 420-480 nm and 550-647 nm to image the $\mathrm{nZnO}$ particles and lipid layer, respectively. The pinhole was set to 0.95 airy units correlating to a $0.6 \mu \mathrm{m}$ section.

Viability.-Jurkat T cells (ATCC TIB-152) were cultured in log phase using RPMI 1640 media supplemented with 10\% FBS (fetal bovine serum), $1 \%$ penicillin/streptomycin and 2 
mM L-glutamine per ATCC (American Type Culture Collection) recommendations. For viability assessments, the cells were first washed with PPH free RPMI 1640 and then seeded at a concentration of $2.5 \times 10^{5}$ cells $/ \mathrm{mL}$ using the same media in a 96 well plate. A stock of $\mathrm{nZnO}$ was prepared at $4.07 \mathrm{mg} / \mathrm{mL}(50 \mathrm{mM})$ and sonicated for 10 minutes. The stock solution was added to fresh cellular media to achieve a final $\mathrm{nZnO}$ concentration of 1.63 $\mathrm{mg} / \mathrm{mL}(20 \mathrm{mM})$ and sonicated for an additional 10 minutes. The cells were then treated at the indicated concentrations and incubated at $37^{\circ} \mathrm{C}$ and $5 \% \mathrm{CO}_{2}$ for 48 hours. Cell viability was assessed using the Alamar Blue metabolic assay where Alamar blue was added to the wells at a final concentration of $10 \% 44$ hours post treatment and incubated for an additional 4 hours. The fluorescence intensity measurements were performed using a Biotek Synergy MX plate reader using an excitation/emission of 530/590 nm.

\section{RESULTS AND DISCUSSION}

\section{ZnO Nanoparticle Synthesis and Characterization}

Polyvinylpyrrolidone (PVP) is known to modify the structure and morphology of many different NMs, including metal oxide NPs. ${ }^{28}$ The inclusion of PVP in synthesis procedures has been shown to act as a surfactant, stabilizing agent, dispersant, binding agent and a capping agent to obtain better dispersions of hydrophobic materials. ${ }^{28}$ In this report, it was determined that the PVP content, annealing temperature and the ratio of water to zinc acetate $(\mathrm{ZnAc})$ were the three key factors that affect the defect states of $\mathrm{nZnO}$. The as-prepared $\mathrm{nZnO}$, to which various amounts of PVP were added pre-synthesis, produced $\mathrm{nZnO}$ with an average crystal sizes near $10 \mathrm{~nm}$ in all cases (Figure S1A-C). Similar methods, though lacking PVP, have demonstrated the ability to control the average crystal size of the $\mathrm{nZnO}$ by varying the amount of water added during synthesis to produce $\mathrm{nZnO}$ with a broad range of sizes - from $\sim 4 \mathrm{~nm}$ to $\sim 50 \mathrm{~nm}$ or greater. The addition of PVP into the solution with the zinc precursor (2:1 PVP:ZnAc; w/w) removed the ability to control the size of the particles, regardless of the ratio of water to zinc acetate. For this reason, any changes in the physical properties of these newly synthesized $\mathrm{nZnO}$ are not size related effects. It is possible that PVP is coordinating the growth of the NPs in the cavities of the polymer and/or capping the particles which restrict their growth, as theorized in reports for other types of NPs. ${ }^{28}$

In our procedure described here, the $\mathrm{nZnO}$ produced have a similar morphology to that in other reports; nearly spherical $\mathrm{ZnO}$ crystals that form spherical aggregates (Figure S1). One consequence of including PVP in the synthesis is that the as-prepared NPs retained some of the polymer and other species from the precursors and solvents. Annealing was performed to remove residual polymer and precursor species to obtain a highly pure nZnO sample. The Thermogravimetric Analysis (TGA) plot of nZnO synthesized with PVP (Figure 1A) demonstrates that after only 10 minutes of annealing at $450^{\circ} \mathrm{C}$, no additional mass loss is evident, even when increasing the temperature to $575^{\circ} \mathrm{C}$. To confirm the complete loss of retained chemical species, FTIR was utilized to evaluate the removal of the retained chemical species in the sample when annealed at various temperatures for 10 minutes. As seen in Figure 1B, after reaching $450^{\circ} \mathrm{C}$, all the bands associated with the precursors and PVP have effectively been removed and even the band associated with $\mathrm{O}-\mathrm{H}$ stretching group at $\sim 3400 \mathrm{~cm}^{-1}$ is almost entirely eliminated. XPS confirmed the results of the post annealed 
samples, with only zinc, oxygen, and carbon atoms (associated with carbon dioxide) detected in the spectra (see SI figure S2). Since all the surface coatings and retained species from the synthesis method were annealed away after 10 minutes at $450^{\circ} \mathrm{C}$, all subsequent experiments annealed the samples at $500^{\circ} \mathrm{C}$ for 10 minutes to ensure complete removal of impurity species unless otherwise noted.

As annealing can induce crystal growth, XRD analysis was performed and it was determined that the average crystal size was $\sim 15 \mathrm{~nm}$; an increase of only $\sim 5 \mathrm{~nm}$ (See SI Figure S1D-F). The modest increase in $\mathrm{nZnO}$ size was confirmed with TEM. It was noteworthy that upon thermal treatment the color of the samples visibly changed from an off-white to light yellow. It was this observation that prompted further investigation into the physical and optical properties of these $\mathrm{nZnO}$. Through these evaluations, we demonstrate that certain modifications to the synthesis procedure allow control of the relative number of defects present within these $\mathrm{nZnO}$.

Raman spectroscopy was employed to investigate the potential changes in vibrational properties, verify the sample purity and assess defects induced during the synthesis and annealing procedure. Figure 2 shows the low temperature (10 K) resonant UV Raman spectra ( $325 \mathrm{~nm}$ excitation) for bulk $\mathrm{ZnO}$ and three samples of the $\mathrm{nZnO}$ produced with varying PVP to zinc acetate ratios. The $\mathrm{E}_{1}$ longitudinal (LO) phonon modes are enhanced under resonant conditions. In the bulk $\mathrm{ZnO}$ sample, the first-order $\mathrm{LO}$ phonon peak appears at $584 \mathrm{~cm}^{-1}$ and the second-order (two-phono) peak appears at $1164 \mathrm{~cm}^{-1} \cdot{ }^{29-31}$ Interestingly, a systematic downward shift of the LO phonon peaks was observed with increasing PVP content. The initial downward shift of the peak, when compared to the bulk $\mathrm{nZnO}$ sample ( 580 vs $584 \mathrm{~cm}^{-1}$ ), is likely due to phonon confinement associated with the smaller particle sizes. ${ }^{32-34}$ However, as discussed above, all the $\mathrm{nZnO}$ samples produced were $\sim 15 \mathrm{~nm}$ in crystal size, so the continued shift of the peak, down to $574 \mathrm{~cm}^{-1}$ for the sample with the highest PVP content, is not likely due to phonon confinement from decreasing crystal size. The systematic shift of the phonon peak correlates with the increasing intensity of the peak that appeared in the spectra at $470 \mathrm{~cm}^{-1}$. The $\mathrm{E}^{2}$ (High) phonon mode that should appear at $437 \mathrm{~cm}^{-1}$ was ruled out as being responsible for the peak found at $470 \mathrm{~cm}^{-1}$, due to the large frequency difference, the fact that it was not observed in the bulk $\mathrm{ZnO}$ and is not commonly seen in resonant Raman spectra of $\mathrm{ZnO} .{ }^{31,35}$ As we noted, the intensity of this peak increased with increasing PVP content. We attribute this peak to defect(s) present in the $\mathrm{nZnO}$ because all the residual impurities retained from the synthesis procedure were removed during the annealing process. Increasing amounts of defects would also explain the continued shift of the LO phonon modes to lower wavenumbers. As the defect concentration increases, the phonon mean free path would decrease due to scattering by defects, therefore shortening the effective phonon confinement length and inducing the observed systematic shift of the peak, ${ }^{36}$ similar to size related phonon confinement. To further investigate the defect(s) responsible for the origin of the peak found at $470 \mathrm{~cm}^{-1}$, photoluminescence was employed.

Photoluminescence (PL) is often utilized to assess nZnO-associated defects as they produce various energy states and optical transitions that are within the band gap region. Numerous papers have reported on how the different emission peaks relate with various defects ${ }^{35}$, 37-42, 
but many of the conclusions remain controversial. Oxygen related defects are often present in $\mathrm{ZnO}$ and are believed to be responsible for the broad green emission $(\sim 500-700 \mathrm{~nm})$ seen in PL. In our attempt to determine the origin of the defects present in these samples, low temperature $(10 \mathrm{~K}) \mathrm{PL}$ was collected and associated with the energy transition modes commonly reported in the literature. Given the systematic shift of the LO phonon modes and the new peak that was observed in the Raman spectra, PL was first collected for samples that have various ratios of PVP to zinc acetate (PVP:ZnAc; w/w), while water content and annealing temperature were held constant. As seen in Figure 3A, varying the ratio of PVP systematically altered the PL emission spectra as it did in Raman spectroscopy. Modest changes were noted in the lower PVP:ZnAc ratios, but a significant broadening of the emission peak evolved as the ratio increased indicating an increased number of defects present that correlates to the PVP content used in the synthesis procedure. At the highest PVP ratios, the difference in PL emissions was negligible. As such, subsequent synthesis studies varying the annealing temperature and water content utilized the 2:1 PVP:ZnAc for the synthesis.

Utilizing the nZnO sample produced with a PVP to zinc acetate ratio of 2:1, additional PL spectra were obtained to evaluate how the changes in surface chemistry, from annealing at various temperatures, impacted the emissions of the sample. As seen in Figure 3B, the asprepared sample's PL spectrum has a peak centered at $\sim 365 \mathrm{~nm}$, which is potentially influenced by the retained species from the precursors on the surface of the particles. However, even after annealing at $350^{\circ} \mathrm{C}$, the temperature at which the majority of the impurities were removed (Figure 1), the PL emission has an apparent red-shift and the peaks are better defined. Once annealing temperature reaches $400^{\circ} \mathrm{C}$, the PL emission peak starts to broaden and extends into the visible region indicating the emergence of defects, possibly by diffusion of zinc ions that were originally associated with the retained PVP. Since the samples annealed at or above $450^{\circ} \mathrm{C}$ are highly pure $\mathrm{nZnO}$, the origin of the visible emission is most likely due to defects in the crystal structure and not from interactions between $\mathrm{ZnO}$ and retained chemical species from the precursors. At annealing temperatures above $500^{\circ} \mathrm{C}$, only modest changes are observed in the violet/blue range of the PL spectra, but the broad defect-related green emission peak around $575 \mathrm{~nm}$, often attributed to oxygen vacancies, ${ }^{43}$ becomes evident. Since the focus of this report is primarily to obtain a highly pure $\mathrm{nZnO}$, relatively free of defects related to the broad green emission (oxygen vacancies), all subsequent samples were made with a 2:1 PVP:ZnAc ratio and annealed at $500^{\circ} \mathrm{C}$.

The final component varied in the synthesis procedure was the volume of water added to the solution (Figure 3C). According to published reports on a similar method, the precise control of the $\mathrm{nZnO}$ crystal size is dependent upon the ratio of water to zinc acetate, ${ }^{26}$ as water is a source for the oxidation of the zinc ions during the Ostwald ripening process. As discussed previously, there were no changes to the crystal size found by varying the amount of water added during this synthesis procedure and therefore we ruled out effects due to alterations in the crystal size. Surprisingly, it was observed that the ratio of water to zinc acetate had a more significant impact on the formation of defect states than the ratio of PVP to ZnAc or the annealing temperature (Figure 3C). Low ratios of water in the synthesis procedure create a zinc-rich environment, potentially allowing for the production of intrinsic defects such as interstitials and antisites, as well as large portions of the crystal surface terminating in zinc 
atoms. A systematic change in the PL emission was demonstrated but it was noted that increasing amounts of water drastically reduced the strong emission near and above $400 \mathrm{~nm}$. The single emission peak at $368 \mathrm{~nm}$, which correlates with the commonly reported nearband-edge emission, is the only significant peak noted at higher water to $\mathrm{ZnAc}$ ratios. Its presence could be due to the reduction of zinc to oxygen ratios, creating a more balanced zinc to oxygen environment, therefore, allowing for better oxidation and formation of the crystals. From these results, we utilized the particles made with a 1:5 water to zinc acetate $(\mathrm{w} / \mathrm{w})$ ratio for fluorescence imaging studies.

The systematic control of PL emission spectra associated with defects present in our $\mathrm{nZnO}$ samples was achieved by varying the PVP content, annealing temperature and water ratios. Numerous batches of NP samples were produced by this method in order to ensure reproducibility of the desired material properties based on the synthesis conditions. To demonstrate the significant changes in the defect content utilizing this new method, the PL emission spectra of other ZnO NPs, synthesized using a variety of methods, were also plotted and compared with our $\mathrm{nZnO}$ sample found to contain the strongest emissions in the violet/blue region (Figure 3D). A good majority of papers published have focused on the defects related to the broad green emissions observed near $575 \mathrm{~nm}$ in $\mathrm{nZnO}$, as seen in the spectra of $\mathrm{ZnO}$ NPs produced using ethanol as a solvent (Figure 3D). This emission is generally attributed to oxygen vacancies and several of these reports focus on the origin of this feature and ways to induce its formation. However, as the inclusion of PVP largely restricts the formation of the defects responsible for this broad peak in this synthesis procedure, we chose to further investigate the emission in the $365-450 \mathrm{~nm}$ range induced by this method.

To get reasonably well assigned peak positions, PL emission spectra with well-defined peaks were first deconvoluted (Figure 4A). These peak positions were then assigned to the spectra generated from the $\mathrm{nZnO}$ that contained a relatively large number of defects and broad peaks in the violet to blue region. As seen in Figure 4A, only four significant peaks were found that contribute to the emissions of the sample produced with a low number of defects. The main peak at $3.36 \mathrm{eV}(369 \mathrm{~nm})$ is related to the band gap of the material and the peak found at $3.32 \mathrm{eV}(374 \mathrm{~nm})$ is attributed to free excitons. ${ }^{39}$ The peak found at $3.24 \mathrm{eV}(383 \mathrm{~nm})$ has been reported as a phonon replica of the exciton peak and the last peak found at $3.07 \mathrm{eV}$ is often attributed to zinc vacancies. In contrast, the sample with a relatively high number of defects (Figure 4B) was determined to contain seven different peaks. The main contributors to the broadening of the emissions were found at positions that have been reported to be related to transitions involving zinc interstitials and zinc vacancies. The three new major peaks near $3.14 \mathrm{eV}, 3.07 \mathrm{eV}$ and $2.97 \mathrm{eV}$ are often attributed to transitions from zinc interstitials to the valence band, the conduction band to zinc vacancies and the conduction band to oxygen interstitials respectively. ${ }^{39}$ It is also possible that some of these emissions may arise from interface traps as reported for $\mathrm{ZnO}$ thin films ${ }^{44}$, as the crystals are bound together in aggregates. There has been no clear consensus on which defects are responsible for the observed emission in this region. A report employed both PL and positron annihilation spectroscopy, which found both techniques to be well correlated when assessing defects states in $\mathrm{ZnO} .{ }^{45}$ This paper evaluated $\mathrm{ZnO}$ with a similar violet-emissions with the main peak centered at $\sim 434 \mathrm{~nm}$ and related the peak to zinc interstitials and zinc vacancies. 
Various experimental procedures have assigned specific peak positions to the various native defect states, whereas reports relying on theoretical calculations have demonstrated that some of these defects are unlikely to occur due to diffusion rates and the required formation energies. ${ }^{23-25}$ However, with the numerous reports relating PL spectra to the various defects, it is likely that zinc interstitials are the major contributor to the strong emissions observed near $400 \mathrm{~nm}$. Regardless of the origin of the defects, many are regarded as donors in the $\mathrm{n}$ type conductivity of $\mathrm{ZnO}$. Since a relatively high number of these defects are present, we wanted to evaluate how these defects affect the band gap of our new samples.

UV-Vis diffuse reflectance spectra were recorded to determine the influence these defects have on the optical band gap of the material. For reference, $\mathrm{nZnO}$ produced using the most similar reported method was plotted against some of the new samples. As can be seen in Figure 5, the samples produced using different ratios of PVP and annealed at $500^{\circ} \mathrm{C}$ induce a significant shift of the band gap. The $\mathrm{ZnO}$ NP sample produced using a similar synthesis procedure, though lacking PVP and annealing, produced $\mathrm{nZnO}$ with a band gap estimated at $\sim 3.31 \mathrm{eV}$, which is close to the commonly excepted value of $3.37 \mathrm{eV}$. This sample was chosen for comparison as it utilizes a similar synthesis procedure, which produced NPs with nearly identical crystal and aggregate sizes, therefore ruling out band-bending effects due to changes in the particle size. However, the samples produced with the new method that have relatively high concentrations of defects, created a dramatic shift of the band gap to as low as $3.08 \mathrm{eV}$. This change of almost $0.3 \mathrm{eV}$ from the commonly accepted value of the band gap is usually obtained through doping of other elements into the crystal lattice.

To verify the lack of metal impurities that may contribute to the observed shift of the band gap, ICP-MS measurements were performed. When compared to the $\sim 2500 \mathrm{ppb}$ of zinc ions from the $\mathrm{nZnO}$, less than $1 \mathrm{ppb}$ of metal contamination was detected (See SI Table S1). Since FTIR, XPS, and ICP-MS all demonstrate the lack of impurities, coupled with the evaluation using Raman and PL, we concluded that the alterations in the properties of these new $\mathrm{nZnO}$ are related to defects induced by this synthesis method and are not related to changes in the crystal size, retained chemical species or impurities.

While many have demonstrated band gap modulation through doping, others have also shown negative Burstein-Moss effects or band gap narrowing induced by oxygen related defects in $\mathrm{nZnO}^{46}$ With the lack of impurities found in the $\mathrm{nZnO}$ described in our report, the band gap narrowing (Figure 5) is attributed to a large number of defects present in the crystal structure, most likely zinc interstitials. The PL spectra in Figure $4 \mathrm{~b}$ further strengthens this argument as the major peak is situated near $3.1 \mathrm{eV}$. Since a large number of defects are present, the additional energy transition modes that generated the observed violet-blue emissions changed the density of states for these $\mathrm{nZnO}$ and lowered the optical band gap. While these changes in the electronic band structure altered the optical band gap of the material, the higher energy transitions are still present, creating the broad emissions peak that extends from the UV region up to $\sim 2.8 \mathrm{eV}(\sim 440 \mathrm{~nm})$ observed in the PL experiments. Figure S4 depicts an energy level diagram of the various transition modes believed to be present in these $\mathrm{nZnO}$. With the dramatic shift of the optical band gap from these defects and since a relatively narrow emission was created in the visible region, studies were performed utilizing these new $\mathrm{nZnO}$ for bio-imaging applications. 


\section{Fluorescence Imaging}

Fluorescence microscopy was employed to assess whether the new $\mathrm{nZnO}$ could be imaged based on their changes in optical properties and the observed shift of the optical bandgap to $\sim 3.1 \mathrm{eV}(400 \mathrm{~nm})$. Confocal microscopy is commonly used in biological imaging and the instrument is generally configured with a $405 \mathrm{~nm}$ laser to image fluorescent dyes such as DAPI or Hoechst that stain the nuclei of cells. A $405 \mathrm{~nm}$ excitation source is generally the highest energy of light available with most conventional fluorescent microscopes which limits the ability of $\mathrm{nZnO}$ to be fluorescently tracked as the band gap of $\mathrm{ZnO}$ is typically near $3.37 \mathrm{eV}$. Since the optical band gap of these new $\mathrm{nZnO}$ is near $400 \mathrm{~nm}$, we attempted to use the $405 \mathrm{~nm}$ laser as an excitation source to fluorescently image these new nZnO. Figure 6A shows the emission spectra recorded using the confocal microscope. When compared to the broad green emission spectra typically seen in $\mathrm{nZnO}$ containing a large number of oxygen vacancies, a relatively narrow emission peak was recorded for this new $\mathrm{nZnO}$ and is easily distinguishable from other commonly used fluorescent stains. To demonstrate that the fluorescence stems from the NPs, fluorescence and bright field images were collected by individual detectors and overlaid (Figure 6B-D). Additional higher resolution and magnification images of the $\mathrm{nZnO}$ are available in the supporting information (Figure S5).

The toxicity of $\mathrm{nZnO}$ could be a potential obstacle for its use as a potential bio-imaging tool as $\mathrm{ZnO}$ has been shown to be toxic to a variety of cell types when produced at the nanoscale. With the changes to the physical properties of these new $\mathrm{nZnO}$, toxicity evaluations were performed to assess concentration at which they become toxic to cells. As seen in Figure 7, concentration up to $100 \mu \mathrm{M}$ showed no apparent toxicity to Jurkat cells after 48 hours of treatment. This is in stark contrast to cadmium-based quantum dots which have been shown to be toxic towards cells in the nanomolar range. ${ }^{7}$ In addition to potential bio-label applications these new $\mathrm{nZnO}$ may allow for investigations into the controversial toxicity mechanisms of $\mathrm{nZnO}$ by tracking their interactions with cells and may help decipher the reason(s) behind their demonstrated cell type selective toxicity.

Another obstacle to the development of new imaging modalities is photobleaching. Photobleaching is the irreversible alteration of a dye or fluorophore leaving it unable to fluoresce and is a common issue in immunofluorescent imaging. The emergence of fluorescent quantum dots, such as CdSe, demonstrate that NMs hold certain advantages over other more traditionally used fluorescent stains, such as their narrow emission spectra, longer fluorescence decay time and their ability to resist photobleaching. ${ }^{5}$ In order to assess the ability of our new $\mathrm{nZnO}$ to resist photobleaching, their fluorescent signal was monitored over time during continuous exposer to laser light. Specifically, $\mathrm{nZnO}$ were excited with a $405 \mathrm{~nm}$ laser for twenty minutes and single plane images were acquired every minute. Time series were collected utilizing different objectives, and regardless of the magnification, no changes in fluorescence were detected (See Figure 8). Since the images might appear to be replicates, each time series was exported into a video format to further demonstrate the stability of the NPs over time (See SI Video). High magnification and resolution images (Figure S5) demonstrate that the large agglomerates seen are comprised of the smaller aggregates seen in the TEM images (Figure S1). Additionally, absorbance, fluorescence 
emissions and quantum yield measurements were performed and are available in the supporting information (Figure S6 and Table S2).

Some of the problems associated with using $\mathrm{nZnO}$ in bio-imaging are due to the broad green emission peak associated with surface defects. When introduced into biological media, various components such as carbonates and phosphates react with the surface of $\mathrm{nZnO}^{10-12,47,48}$ and can potentially reduce or completely remove the fluorescence associated with surface defects. In our new $\mathrm{nZnO}$, the defects in this system can persist throughout the crystal lattice, such as zinc interstitials, and perhaps stabilize their ability to fluoresce even in cellular media. Having a pure, unmodified and naturally fluorescent $\mathrm{nZnO}$ sample that is excitable with a laser source commonly available in fluorescent microscope systems can expand the use of $\mathrm{nZnO}$ in fluorescence imaging studies. In addition, a stably fluorescent $\mathrm{nZnO}$ will also facilitate research focused on understanding $\mathrm{nZnO}$ interactions with living systems.

To demonstrate the ability to image $\mathrm{nZnO}$ in cellular media conditions, live-cell imaging was performed using T47D breast cancer cells. A stock solution of $\mathrm{nZnO}$ was prepared by sonicating $4.07 \mathrm{mg} / \mathrm{mL}$ of $\mathrm{nZnO}$ in nanopure water for 20 minutes. The cells were treated with $30 \mu \mathrm{g} / \mathrm{mL}$ of $\mathrm{nZnO}$ and incubated for either 2 or 24 hours. Cells were then stained with CellMask Orange Plasma Membrane for 30 minutes prior to imaging. For a control, untreated T47D cells were stained with CellMask Orange only and imaged using the same configuration and laser settings in order to rule out any autofluorescence generated by the cells in the $\mathrm{nZnO}$ channel. As seen in Figure 9, the untreated cells have little to no apparent fluorescence in the $\mathrm{nZnO}$ channel. After 2 hours of incubation, a few $\mathrm{nZnO}$ are seen in the same plane as the cells and appear to have begun the agglomeration and sedimentation process commonly seen with NPs, ${ }^{49-51}$ causing association with the lipid membrane on the surface of the cells. No apparent changes in cellular morphology were noted at this time point. Surprisingly, after 24 hours of $\mathrm{nZnO}$ exposure, no particles were found near the exterior of the cells, and in stark contrast to the fluorescence observed at 2 hours, the only fluorescence detected appears to be from $\mathrm{nZnO}$ that have been internalized within the plasma membrane. It is unlikely that every NP was internalized by the cells, yet no particles could be found in the exterior. It is possible that the non-internalized $\mathrm{nZnO}$ underwent dissolution or transformed into zinc carbonate or hydroxide species and were no longer fluorescent. However, many NPs were still detectable in the interior of the cells after 24 hours and may resist degradation or transformation upon cellular internalization. Another noteworthy feature from this experiment was that the morphology of the T47D cells changed dramatically. The cells rounded up and appear to be detaching from the culture plate. Furthermore, cells showed evidence of blebbing; the bulging of the cell membrane, characteristic of cytoskeletal breakdown that accompanies apoptosis.

Despite the number of studies that investigate $\mathrm{nZnO}$, many questions remain regarding toxicity mechanisms and their inherent selectivity towards cancer cell destruction. Some of the more commonly cited mechanisms of $\mathrm{nZnO}$ toxicity has been attributed to ROS generation, particle dissolution, and to a lesser extent, membrane damage. ${ }^{1,52-55}$ Since there is still controversy on the primary source of toxicity, the unmodified fluorescent $\mathrm{nZnO}$ described here may help elucidate the various toxicity mechanism(s) and give insight into 
why reports demonstrate cell type selective toxicity. Even after 24 hours post treatment, a $\mathrm{nZnO}$ fluorescence signal was still detectable in the interior of the cells and may suggest NP internalization is key to asserting the NPs toxic effects. However, even though these interesting observations were made, the source(s) of the changes in cellular morphology were not deciphered and is the goal of future projects. Utilization of zinc ion specific dyes may allow for simultaneous tracking of both $\mathrm{nZnO}$ and the release of zinc ions from $\mathrm{nZnO}$ dissolution to help elucidate the complex nature of these interactions. Other specific labels, such as fluorophores specific to various endocytic processes and ROS sensitive dyes, would be keys to understanding the interactions of the $\mathrm{nZnO}$ with cells but is beyond the scope of this paper. Other future work will investigate reducing the size of the aggregates through additional modifications to the synthesis procedure and through mechanical processes such as utilizing a ball mill, stabilizing the particles in solution and conjugating antibodies to the surface of the NPs to facilitate their use as a potential bio-label for targeting specific cellular compartments.

\section{CONCLUSION}

Achieving systematic control of native defects in $\mathrm{ZnO}$ NPs can often be challenging, especially in wet chemical methods. This work demonstrates the ability to control specific defect-states of $\mathrm{nZnO}$ through modifications to the synthesis that modulate key properties of the material. Other reports have also targeted the defect related blue emission in $\mathrm{nZnO}$ and have demonstrated the ability to produce blue emitting nanoparticle NPs when excited. ${ }^{56-59}$ While these particles have utility in a variety of applications, most of these reports show that impurities are still present, mainly from the precursors or capping agents. To our knowledge, none have demonstrated a reduction in the band gap allowing for non-UV excitation sources to produce sufficient emissions to fluorescently image the NPs. A recent review article surveyed numerous papers about the luminescent properties and biological applications of nZnO. ${ }^{60}$ Multiple novel approaches to creating luminescent particles, including defect related emissions have been reported. However, many of these particles required modification through different capping agents, doping and conjugations. Notably, many of them still required the use of UV excitation to produce emissions.

The combination of the changes to the physical properties that arises from the relatively high number of defects, likely zinc interstitials, allows these new $\mathrm{nZnO}$ to be used in ways not previously described. The reduction of the band gap to $\sim 3.1 \mathrm{eV}$ and the shift of the emission spectra to the visible region allowed for imaging of the NPs using traditional fluorescence microscopy techniques without any other modification such as surface coatings, doping or labeling with fluorescent stains. The ability to perform live cell imaging with essentially pure $\mathrm{nZnO}$ may help in deciphering their complex interactions with various cells types and understanding their cancer cell selective toxicity. Many of these interactions have relied upon end-point effects and imaging pure $\mathrm{nZnO}$ is normally done through TEM based experiments. This opens the door for new methodologies to track $\mathrm{nZnO}$ interactions with live cells in real-time.

As a potential bio-label, the relatively low toxicity of $\mathrm{nZnO}$ compared to other quantum dots such as cadmium chalcogenides may also make them more suitable for fluorescence 
imaging with live cells. However, similar to other quantum dots, further research will be needed to effectively use them as a bio-label such as increasing their stability in aqueous solution and surface conjugation to effectively target them to specific cellular structures. Since the defects responsible for the observed changes to the NP properties are believed to be related to zinc interstitials and not necessarily surface defects, including a passivation layer on the surface may further increase the stability of these new $\mathrm{nZnO}$ in cellular media conditions without interfering with the species responsible for their fluorescent emissions. Additionally, the alterations to the physical properties discussed in this report may also be exploited in a variety of other applications such as optoelectronic devices. Further research is needed to fully investigate their utilization in these various fields but, based on these studies, there is promise for them to be used for numerous applications.

\section{Supplementary Material}

Refer to Web version on PubMed Central for supplementary material.

\section{Acknowledgments}

Funding Sources

This research was supported in part by NSF-MRI awards (\#032,233,\#0722699, \#0521315), and NIH (1R15CA141358-01). We also acknowledge support from the Biomolecular Research Center at Boise State University, COBRE, and INBRE with funding from the NIH Grant Nos. P20GM103408 and P20GM109095, NSF (Nos. 0619793, 0923535), the Idaho State Board of Education and the M. J. Murdock Charitable TrustInstrumentation and Partners in Science programs. The content is solely the responsibility of the authors and does not necessarily represent the official views of the National Institutes of Health.

\section{ABBREVIATIONS}

$\begin{array}{ll}\text { NP } & \text { nanoparticles } \\ \text { NM } & \text { nanomaterials } \\ \text { nZnO } & \text { ZnO nanoparticles } \\ \text { TGA } & \text { thermogravimetric analysis } \\ \text { XRD } & \text { X-ray powder diffraction } \\ \text { XPS } & \text { X-ray photoelectron spectroscopy } \\ \text { ICP-MS } & \text { inductively coupled plasma mass spectrometry } \\ \text { TEM } & \text { transmission electron microscopy } \\ \text { FITC } & \text { fluorescein isothiocyanate } \\ \text { DEG } & \text { diethylene glycol } \\ \text { PVP } & \text { polyvinylpyrrolidone } \\ \text { FTIR } & \text { Fourier transform infrared spectroscopy } \\ \text { PPH free RPMI 1640 } & \text { HEPES, phenol red and phosphate free RPMI 1640 }\end{array}$



ZnAc
zinc acetate
LO
longitudinal
PL
photoluminescence

\section{REFERENCES}

1. Rasmussen JW; Martinez E; Louka P; Wingettt DG, Zinc Oxide Nanoparticles for Selective Destruction of Tumor Cells and Potential for Drug Delivery Applications. Expert Opin. Drug Delivery 2010, 7, 1063-1077.

2. Bora T; Sathe P; Laxman K; Dobretsov S; Dutta J, Defect Engineered Visible Light Active ZnO Nanorods for Photocatalytic Treatment of Water. Catal. Today 2017, 284, 11-18.

3. Djurisic AB; Ng AMC; Chen XY, ZnO Nanostructures for Optoelectronics: Material Properties and Device Applications. Prog. Quantum Electron 2010, 34, 191-259.

4. Hanley C; Layne J; Punnoose A; Reddy KM; Coombs I; Coombs A; Feris K; Wingett D, Preferential Killing of Cancer Cells and Activated Human T cells using ZnO Nanoparticles. Nanotechnology 2008, 19, 10.

5. Resch-Genger U; Grabolle M; Cavaliere-Jaricot S; Nitschke R; Nann T, Quantum Dots Versus Organic Dyes as Fluorescent Labels. Nat. Methods 2008, 5, 763-775. [PubMed: 18756197]

6. Chan WCW; Maxwell DJ; Gao XH; Bailey RE; Han MY; Nie SM, Luminescent Quantum Dots for Multiplexed Biological Detection and Imaging. Curr. Opin. Biotechnol 2002, 13, 40-46. [PubMed: 11849956]

7. Chen N; He Y; Su YY; Li XM; Huang Q; Wang HF; Zhang XZ; Tai RZ; Fan CH, The Cytotoxicity of Cadmium-Based Quantum Dots. Biomaterials 2012, 33, 1238-1244. [PubMed: 22078811]

8. Punnoose A; Dodge K; Rasmussen JW; Chess J; Wingett D; Anders C, Cytotoxicity of ZnO Nanoparticles Can Be Tailored by Modifying Their Surface Structure: A Green Chemistry Approach for Safer Nanomaterials. ACS Sustainable Chem. Eng 2014, 2, 1666-1673. [PubMed: 25068096]

9. Xia T; Kovochich M; Liong M; Madler L; Gilbert B; Shi HB; Yeh JI; Zink JI; Nel AE, Comparison of the Mechanism of Toxicity of Zinc Oxide and Cerium Oxide Nanoparticles Based on Dissolution and Oxidative Stress Properties. ACS Nano 2008, 2, 2121-2134. [PubMed: 19206459]

10. Lv JT; Zhang SZ; Luo L; Han W; Zhang J; Yang K; Christie P, Dissolution and Microstructural Transformation of ZnO Nanoparticles under the Influence of Phosphate. Environ. Sci. Technol 2012, 46, 7215-7221. [PubMed: 22651907]

11. Herrmann R; Garcia-Garcia FJ; Reller A, Rapid Degradation of Zinc Oxide Nanoparticles by Phosphate Ions. Beilstein J. Nanotechnol 2014, 5, 2007-2015. [PubMed: 25383310]

12. Mu QS; David CA; Galceran J; Rey-Castro C; Krzeminski L; Wallace R; Bamiduro F; Milne SJ; Hondow NS; Brydson R; Vizcay-Barrena G; Routledge MN; Jeuken LJC; Brown AP, Systematic Investigation of the Physicochemical Factors That Contribute to the Toxicity of $\mathrm{ZnO}$ Nanoparticles. Chem. Res. Toxicol 2014, 27, 558-567. [PubMed: 24575710]

13. Xiong HM, Photoluminescent ZnO Nanoparticles Modified by Polymers. J. Mater. Chem 2010, 20, 4251-4262.

14. Wang H; Wingett D; Engelhard MH; Feris K; Reddy KM; Turner P; Layne J; Hanley C; Bell J; Tenne D; Wang C; Punnoose A, Fluorescent Dye Encapsulated ZnO Particles with Cell-Specific Toxicity for Potential Use in Biomedical Applications. Journal of Materials Science-Materials in Medicine 2009, 20, 11-22. [PubMed: 18651111]

15. Liu YL; Ai KL; Yuan QH; Lu LH, Fluorescence-enhanced Gadolinium-Doped Zinc Oxide Quantum Dots for Magnetic Resonance and Fluorescence Imaging. Biomaterials 2011, 32, 1185 1192. [PubMed: 21055806]

16. Khan Y; Durrani SK; Mehmood M; Ahmad J; Khan MR; Firdous S, Low Temperature Synthesis Of Fluorescent ZnO Nanoparticles. Appl. Surf. Sci 2010, 257, 1756-1761. 
17. Rotella H; Mazel Y; Brochen S; Valla A; Pautrat A; Licitra C; Rochat N; Sabbione C; Rodriguez G; Nolot E, Role of Vacancy Defects in Al Doped ZnO Thin Films for Optoelectronic Devices. J. Phys. D: Appl. Phys 2017, 50, 7.

18. Ahmad M; Zhao J; Iqbal J; Miao W; Xie L; Mo R; Zhu J, Conductivity Enhancement by Slight Indium Doping in ZnO Nanowires for Optoelectronic Applications. J. Phys. D: Appl. Phys 2009, $42,7$.

19. Gu FB; You D; Wang ZH; Han DM; Guo GS, Improvement of Gas-sensing Property by Defect Engineering in Microwave-Assisted Synthesized 3D ZnO Nanostructures. Sens. Actuators, B 2014, 204, 342-350.

20. Weber MH; Selim FA; Solodovnikov D; Lynn KG, Defect Engineering of ZnO. Appl. Surf. Sci 2008, 255, 68-70.

21. Shi WS; Agyeman O; Xu CN, Enhancement of the Light Emissions from Zinc Oxide Films by Controlling the Post-Treatment Ambient. J. Appl. Phys 2002, 91, 5640-5644.

22. Das D; Mondal P, Photoluminescence Phenomena Prevailing in C-Axis Oriented Intrinsic ZnO Thin Films Prepared by RF Magnetron Sputtering. RSC Adv 2014, 4, 35735-35743.

23. Janotti A; Van de Walle CG, Native Point Defects in ZnO. Phys. Rev. B 2007, 76, 22.

24. McCluskey MD; Jokela SJ, Defects in ZnO. J. Appl. Phys 2009, 106, 13.

25. Alkauskas A; Pasquarello A, Band-edge Problem in the Theoretical Determination of Defect Energy Levels: The O Vacancy in ZnO as a Benchmark Case. Phys. Rev. B 2011, 84, 11.

26. Hanley C; Thurber A; Hanna C; Punnoose A; Zhang JH; Wingett DG, The Influences of Cell Type and $\mathrm{ZnO}$ Nanoparticle Size on Immune Cell Cytotoxicity and Cytokine Induction. Nanoscale Res. Lett 2009, 4, 1409-1420. [PubMed: 20652105]

27. Eixenberger JE; Anders CB; Hermann RJ; Brown RJ; Reddy KM; Punnoose A; Wingett DG, Rapid Dissolution of ZnO Nanoparticles Induced by Biological Buffers Significantly Impacts Cytotoxicity. Chem. Res. Toxicol 2017, 30, 1641-1651. [PubMed: 28693316]

28. Koczkur KM; Mourdikoudis S; Polavarapu L; Skrabalak SE, Polyvinylpyrrolidone (PVP) in Nanoparticle Synthesis. Dalton Trans 2015, 44, 17883-17905. [PubMed: 26434727]

29. Scott JF, UV Resonant Raman Scattering in ZnO. Phys. Rev. B 1970, 2, 1209-\&.

30. Cheng HM; Lin KF; Hsu HC; Hsieh WF, Size Dependence of Photoluminescence and Resonant Raman Scattering from ZnO Quantum Dots. Appl. Phys. Lett 2006, 88, 3.

31. Kumar B; Gong H; Chow SY; Tripathy S; Hua Y, Photoluminescence and Multiphonon Resonant Raman Scattering in Low-Temperature Grown ZnO Nanostructures. Appl. Phys. Lett 2006, 89, 3.

32. Samuel MS; Koshy J; Chandran A; George KC, Optical Phonon Confinement in ZnO Nanorods and Nanotubes. Indian J. Pure Appl. Phys 2010, 48, 703-708.

33. Rajalakshmi M; Arora AK; Bendre BS; Mahamuni S, Optical Phonon Confinement in Zinc Oxide Nanoparticles. J. Appl. Phys 2000, 87, 2445-2448.

34. Lin KF; Cheng HM; Hsu HC; Hsieh WF, Band Gap Engineering and Spatial Confinement of Optical Phonon in ZnO Quantum Dots. Appl. Phys. Lett 2006, 88, 3.

35. Ahn CH; Kim YY; Kim DC; Mohanta SK; Cho HK, A Comparative Analysis of Deep Level Emission in ZnO Layers Deposited by Various Methods. J. Appl. Phys 2009, 105, 5.

36. Richter H; Wang ZP; Ley L, The One Phonon Raman-Spectrum in Microcrystalline Silicon. Solid State Commun 1981, 39, 625-629.

37. Jeong SH; Kim BS; Lee BT, Photoluminescence Dependence of ZnO Films Grown on Si(100) by Radio-Frequency Magnetron Sputtering on the Growth Ambient. Appl. Phys. Lett 2003, 82, 26252627.

38. Cao BQ; Cai WP; Zeng HB, Temperature-Dependent Shifts of Three Emission Bands for ZnO Nanoneedle Arrays. Appl. Phys. Lett 2006, 88, 3.

39. Vempati S; Mitra J; Dawson P, One-Step Synthesis of ZnO Nanosheets: a Blue-White Fluorophore. Nanoscale Res. Lett 2012, 7, 10. [PubMed: 22222097]

40. Tam KH; Cheung CK; Leung YH; Djurisic AB; Ling CC; Beling CD; Fung S; Kwok WM; Chan WK; Phillips DL; Ding L; Ge WK, Defects in ZnO Nanorods Prepared by a Hydrothermal Method. J. Phys. Chem. B 2006, 110, 20865-20871. [PubMed: 17048900] 
41. Vanheusden K; Seager CH; Warren WL; Tallant DR; Voigt JA, Correlation Between Photoluminescence and Oxygen Vacancies in ZnO Phosphors. Appl. Phys. Lett1996, 68, 403-405.

42. Rodnyi PA; Khodyuk IV, Optical and Luminescence Properties of Zinc Oxide (Review). Opt. Spectrosc 2011, 111, 776-785.

43. Vanheusden K; Warren WL; Seager CH; Tallant DR; Voigt JA; Gnade BE, Mechanisms Behind Green Photoluminescence in ZnO Phosphor Powders. J. Appl. Phys 1996, 79, 7983-7990.

44. Lim K; Hamid MAA; Shamsudin R; Al-Hardan NH; Mansor I; Chiu W, Temperature-Driven Structural and Morphological Evolution of Zinc Oxide Nano-Coalesced Microstructures and Its Defect-Related Photoluminescence Properties. Materials 2016, 9, 15.

45. Mishra AK; Chaudhuri SK; Mukherjee S; Priyam A; Saha A; Das D, Characterization of Defects in ZnO Nanocrystals: Photoluminescence and Positron Annihilation Spectroscopic Studies. J. Appl. Phys 2007, 102, 6.

46. Ansari SA; Khan MM; Kalathil S; Nisar A; Lee J; Cho MH, Oxygen Vacancy Induced Band Gap Narrowing of ZnO Nanostructures by an Electrochemically Active Biofilm. Nanoscale 2013, 5, 9238-9246. [PubMed: 23938937]

47. Rathnayake S; Unrine JM; Judy J; Miller AF; Rao W; Bertsch PM, Multitechnique Investigation of the $\mathrm{pH}$ Dependence of Phosphate Induced Transformations of ZnO Nanoparticles. Environ. Sci. Technol 2014, 48, 4757-4764. [PubMed: 24693856]

48. Reed RB; Ladner DA; Higgins CP; Westerhoff P; Ranville JF, Solubility of Nano-Zinc Oxide in Environmentally and Biologically Important Matrices. Environ. Toxicol. Chem 2012, 31, 93-99. [PubMed: 21994124]

49. Cho EC; Zhang Q; Xia YN, The Effect of Sedimentation and Diffusion on Cellular Uptake of Gold Nanoparticles. Nat. Nanotechnol 2011, 6, 385-391. [PubMed: 21516092]

50. Anders CB; Chess JJ; Wingett DG; Punnoose A, Serum Proteins Enhance Dispersion Stability and Influence the Cytotoxicity and Dosimetry of ZnO Nanoparticles in Suspension and Adherent Cancer Cell Models. Nanoscale Res. Lett 2015, 10, 22. [PubMed: 25852320]

51. Hinderliter PM; Minard KR; Orr G; Chrisler WB; Thrall BD; Pounds JG; Teeguarden JG, ISDD: A Computational Model of Particle Sedimentation, Diffusion and target Cell Dosimetry for In Vitro Toxicity Studies. Part. Fibre Toxicol 2010, 7, 19. [PubMed: 20653945]

52. Kao YY; Chen YC; Cheng TJ; Chiung YM; Liu PS, Zinc Oxide Nanoparticles Interfere With Zinc Ion Homeostasis to Cause Cytotoxicity. Toxicol. Sci 2012, 125, 462-472. [PubMed: 22112499]

53. Buerki-Thurnherr T; Xiao LS; Diener L; Arslan O; Hirsch C; Maeder-Althaus X; Grieder K; Wampfler B; Mathur S; Wick P; Krug HF, In Vitro Mechanistic Study Towards a Better Understanding of ZnO Nanoparticle Toxicity. Nanotoxicology 2013, 7, 402-416. [PubMed: 22394310]

54. Xie YP; He YP; Irwin PL; Jin T; Shi XM, Antibacterial Activity and Mechanism of Action of Zinc Oxide Nanoparticles against Campylobacter jejuni. Appl. Environ. Microbiol 2011, 77, 23252331. [PubMed: 21296935]

55. Anders CB; Eixenberger JE; Franco NA; Hermann RJ; Rainey KD; Chess JJ; Punnoose A; Wingett DG, ZnO Nanoparticle Preparation Route Influences Surface Reactivity, Dissolution and Cytotoxicity. Environ. Sci.: Nano 2018, 5, 572-588. [PubMed: 29479436]

56. Fu YS; Du XW; Kulinich SA; Qiu JS; Qin WJ; Li R; Sun J; Liu J, Stable Aqueous Dispersion of ZnO Quantum Dots with Strong Blue Emission via Simple Solution Route. J. Am. Chem. Soc 2007, 129, 16029-16033. [PubMed: 18044896]

57. Jule LT; Dejene FB; Roro KT; Urgessa ZN; Botha JR, Rapid Synthesis of Blue Emitting ZnO Nanoparticles for Fluorescent Applications. Phys. B (Amsterdam, Neth.) 2016, 497, 71-77.

58. Bakrudeen HB; Sugunalakshmi M; Reddy BSR, Auto-Fluorescent Mesoporous ZnO NANOSPheres for Drug Delivery Carrier Application. Mater. Sci. Eng., C 2015, 56, 335-340.

59. Senthilkumar K; Senthilkumar O; Yamauchi K; Sato M; Morito S; Ohba T; Nakamura M; Fujita Y, Preparation of ZnO Nanoparticles for Bio-Imaging Applications. Phys. Status Solidi B 2009, 246, 885-888.

60. Zhang ZY; Xiong HM, Photoluminescent ZnO Nanoparticles and Their Biological Applications. Materials 2015, 8, 3101-3127. 

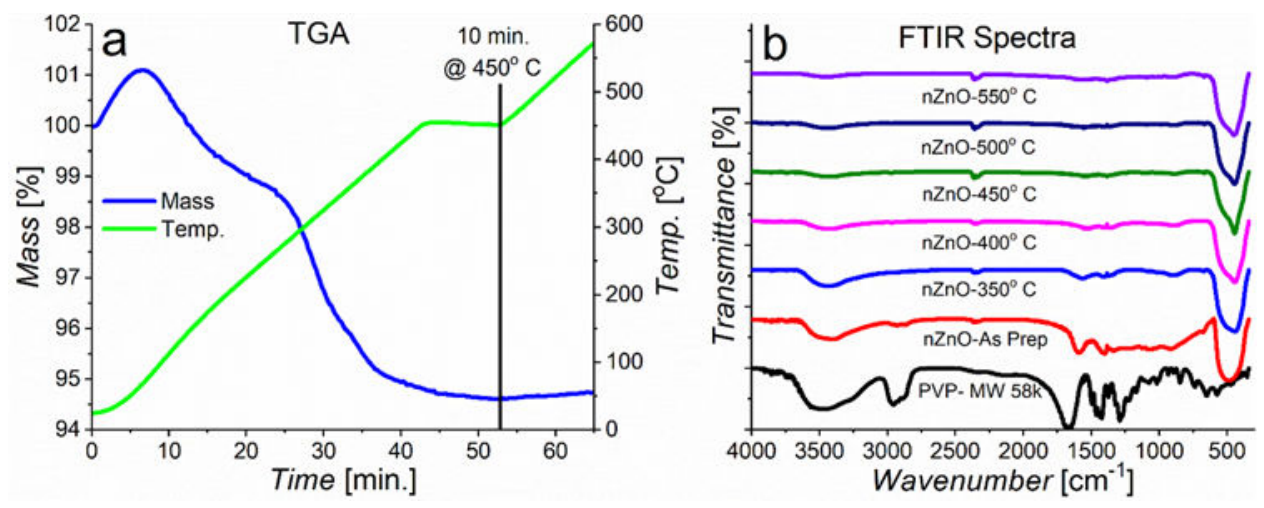

Figure 1.

(a) Thermogravimetric Analysis plot of $\mathrm{nZnO}$ synthesized with Polyvinylpyrrolidone (PVP) demonstrating the mass loss is complete after 10 minutes of annealing at $450^{\circ} \mathrm{C}$. (b) FTIR spectra of pure PVP, the as-prepared (non-annealed) $\mathrm{nZnO}$ and $\mathrm{nZnO}$ annealed at various temperatures for 10 minutes. FTIR data confirms that after 10 minutes of annealing at $450^{\circ}$ $\mathrm{C}$ that no other chemical species from the precursors are retained with the NPs. 


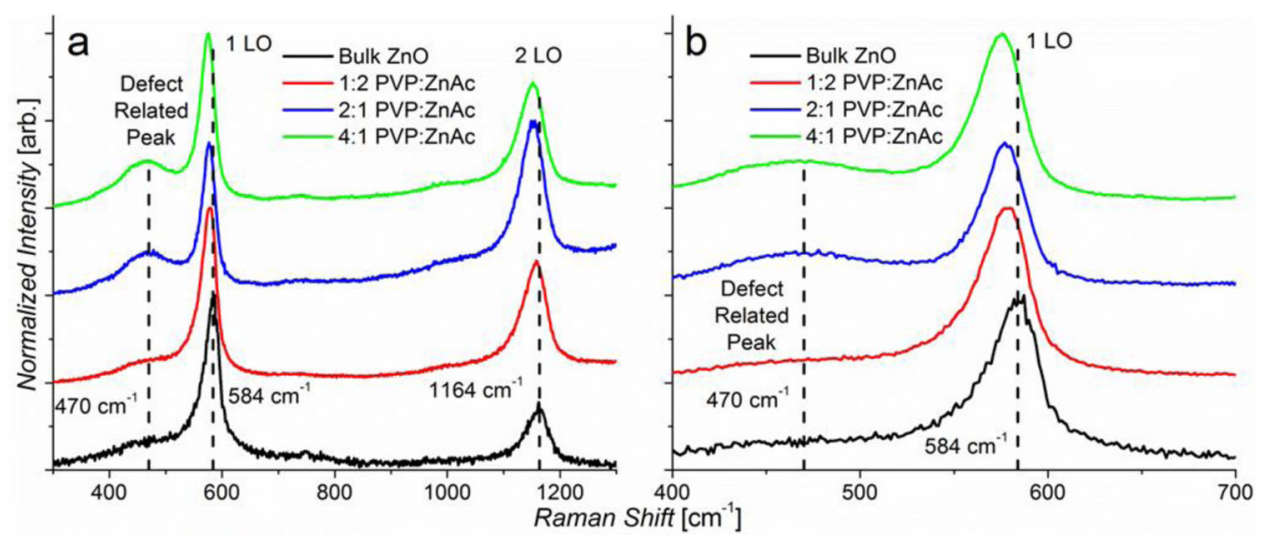

Figure 2.

(a) Low temperature $(10 \mathrm{~K}$ ) resonant Raman spectra (325 nm laser) of bulk ZnO and the $\mathrm{nZnO}$ synthesized with various amount of PVP. Spectra shows a systematic shift of the LO phonon modes as the defect related peak centered at $470 \mathrm{~cm}^{-1}$ increases in area. (b) Zoomed in spectra of the defect related peak and the $1 \mathrm{LO}$ phonon mode to highlight the systematic shift of the peak as the defect related peak increases in area. This systematic shift is likely due to phonon confinement due to increases in defects present in the ZnO NPs. 


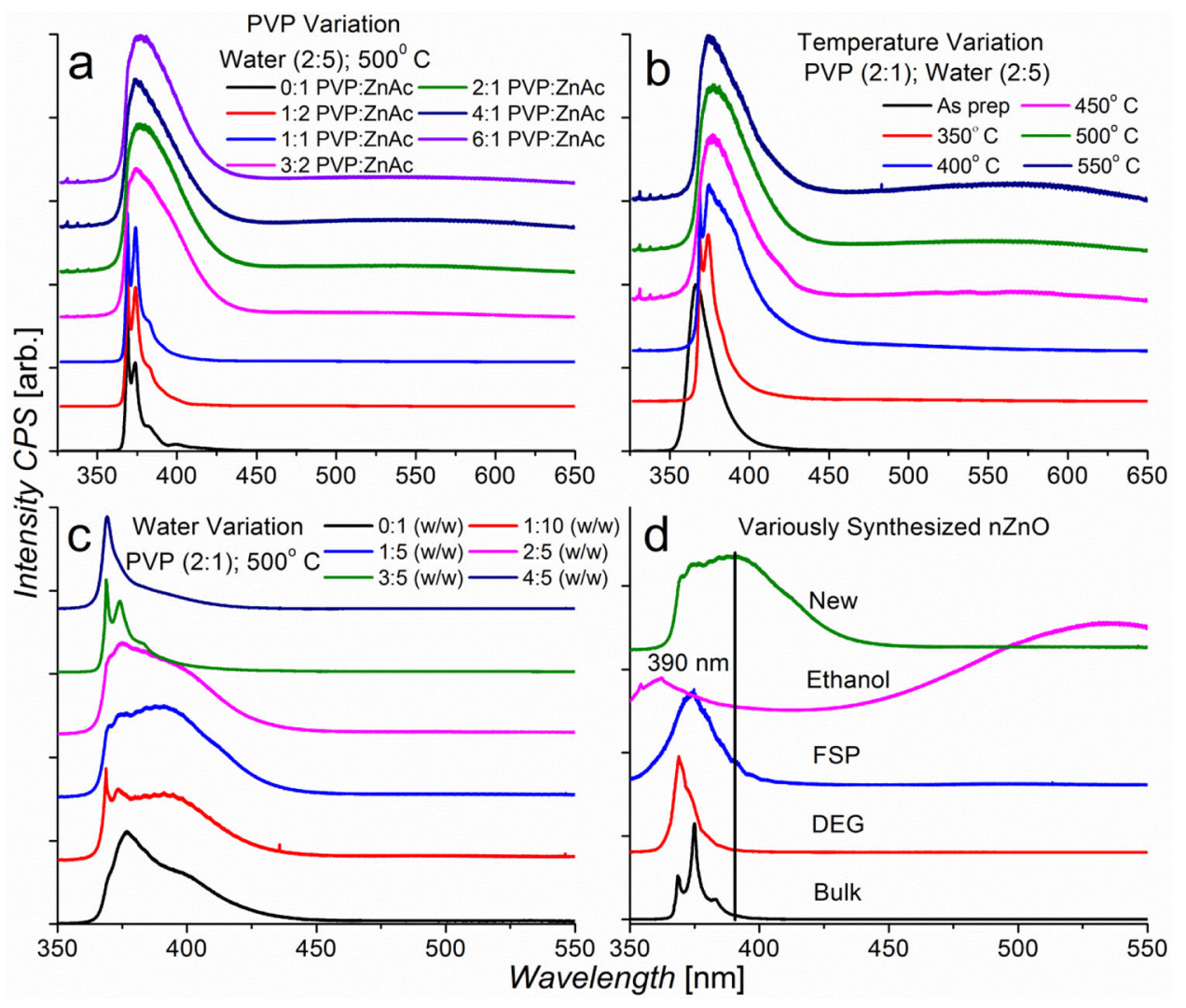

Figure 3.

Low temperature Photoluminescence (PL) spectra of the $\mathrm{nZnO}$ synthesized by varying different parameters in the synthesis procedure. (a) PL spectra of the nZnO synthesized with various amounts of PVP while all other parameters are kept constant. At low PVP:Zinc Acetate $(\mathrm{ZnAc})$ ratios, little change in the PL spectra is noted. As the amount increases, the well- defined peaks broaden and extend into the visible spectrum. (b) PL spectra of the $\mathrm{nZnO}$ annealed at various temperatures. The unannealed sample spectra extends further into the UV range, likely due to the presence of various retained species from the synthesis procedure. As the annealing temperature increase, the main peak in the spectra red-shifts and broadens out to $450 \mathrm{~nm}$. At the highest temperature used, the broad green emission spectra, commonly reported on $\mathrm{nZnO}$, becomes apparent. (c) PL spectra of the $\mathrm{nZnO}$ with various amounts of water added in the synthesis. At relatively high additions of water, the main broad peak narrows likely due to changes from a zinc rich environment to a more balanced oxygen to zinc environment. (d) PL spectra of ZnO NPs synthesized using various methods (ethanol as the solvent, Flame spray pyrolysis (FSP), diethylene glycol as the solvent (DEG) and micron sized (Bulk) $\mathrm{ZnO}$ ) to demonstrate the extreme difference of the new $\mathrm{nZnO}$ compared to other commonly used methods. 


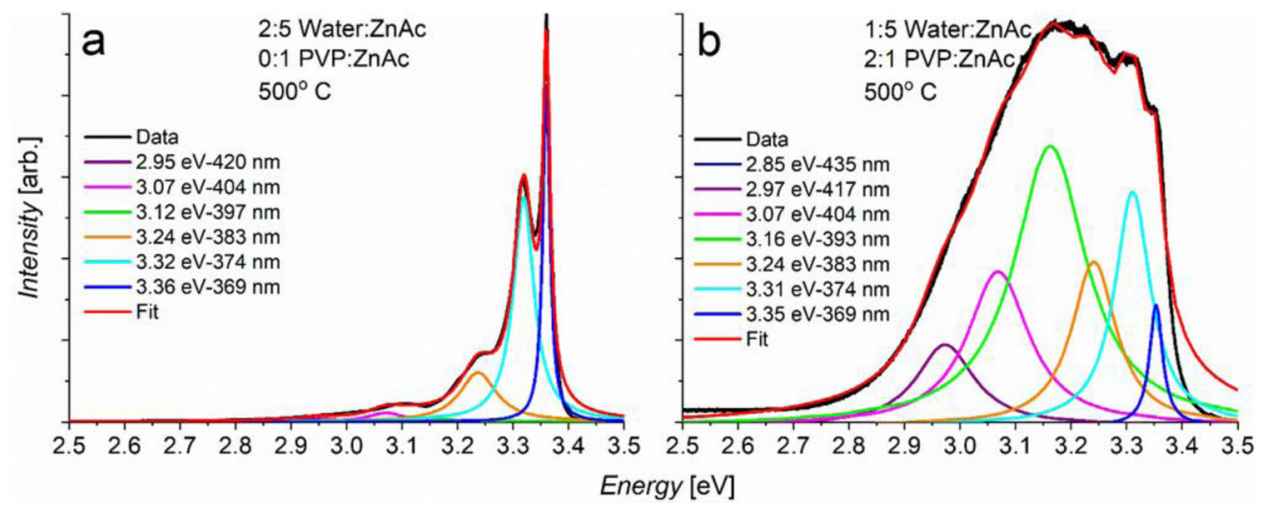

Figure 4.

Deconvolution of the low temperature photoluminescence spectra of $\mathrm{nZnO}$ synthesized with (a) no PVP and (b) a 2:1 (w/w) PVP to zinc acetate ratio. (a) The NPs with low defect states and well-defined peaks were first deconvoluted to assign positions and acquire reasonable peak widths for the near band edge related emissions. (b) The $\mathrm{nZnO}$ sample with a relatively high number of defects shows multiple peaks related to various defects formed during the new synthesis procedure. 


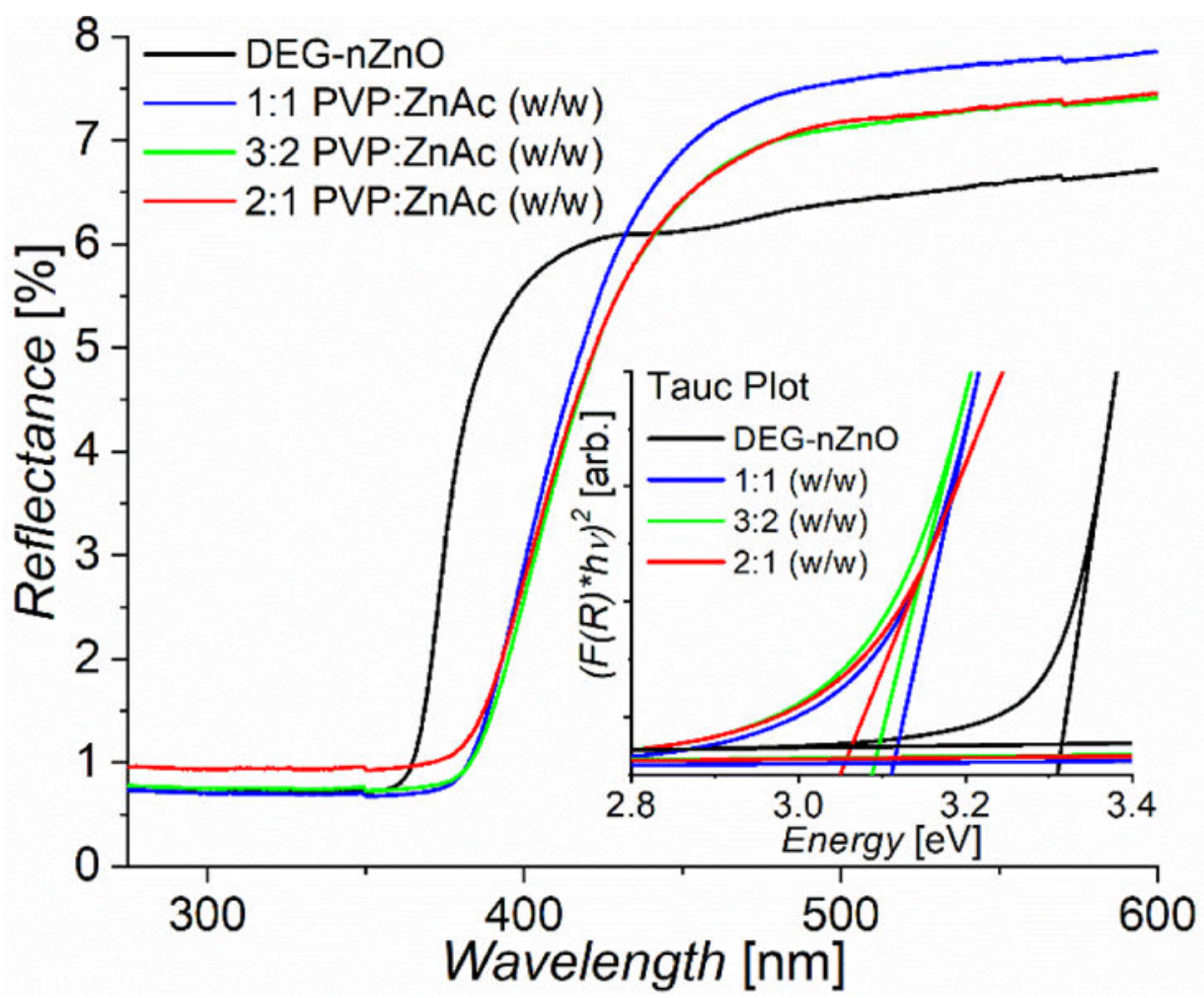

Figure 5.

UV-Vis spectra of the new $\mathrm{nZnO}$ synthesized with various amounts of PVP compared to the most similar reported method using DEG as a solvent. The UV-Vis spectra were converted into a Tauc Plot (inset) to determine the optical band gap of each sample. The DEG method produced $\mathrm{nZnO}$ with an optical band gap of $\sim 3.31 \mathrm{eV}$ whereas the new method shifted the optical band gap to below $3.1 \mathrm{eV}$. 


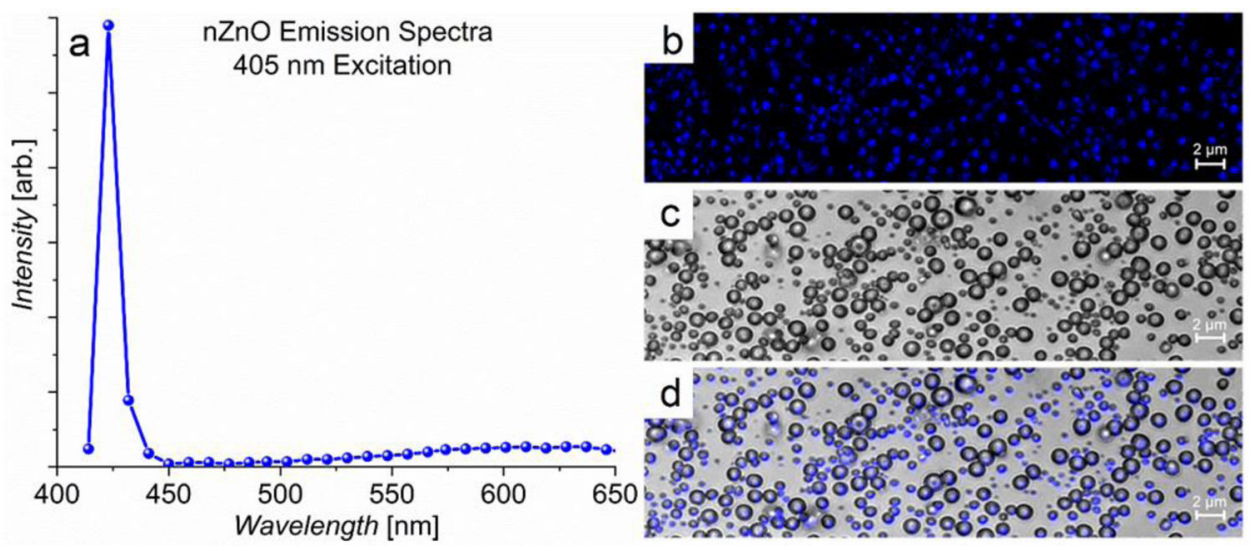

Figure 6.

(a) The emission spectra of the $\mathrm{nZnO}$ recorded with a confocal microscope using a $405 \mathrm{~nm}$ laser as an excitation source. Using a 100x objective, the fluorescence image (b) of the $\mathrm{nZnO}$ and bright field (c) images were collected and overlaid (d) to demonstrate that the fluorescence is from the novel $\mathrm{nZnO}$. 


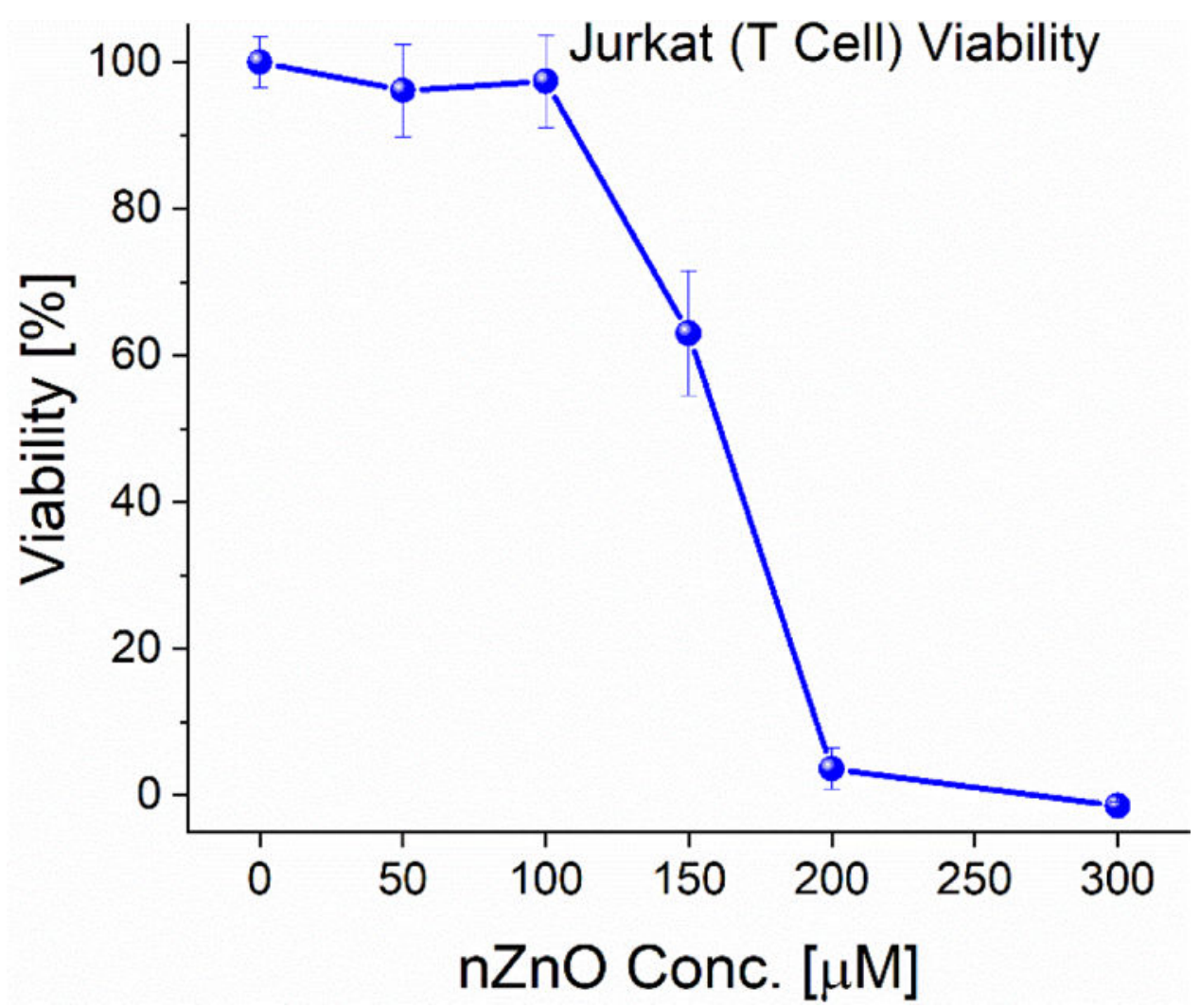

Figure 7.

Viability profile of Jurkat cells after treatment with $\mathrm{nZnO}$ for 48 hours at various concentrations. No apparent toxicity is present for concentrations up to $100 \mu \mathrm{M}$. 

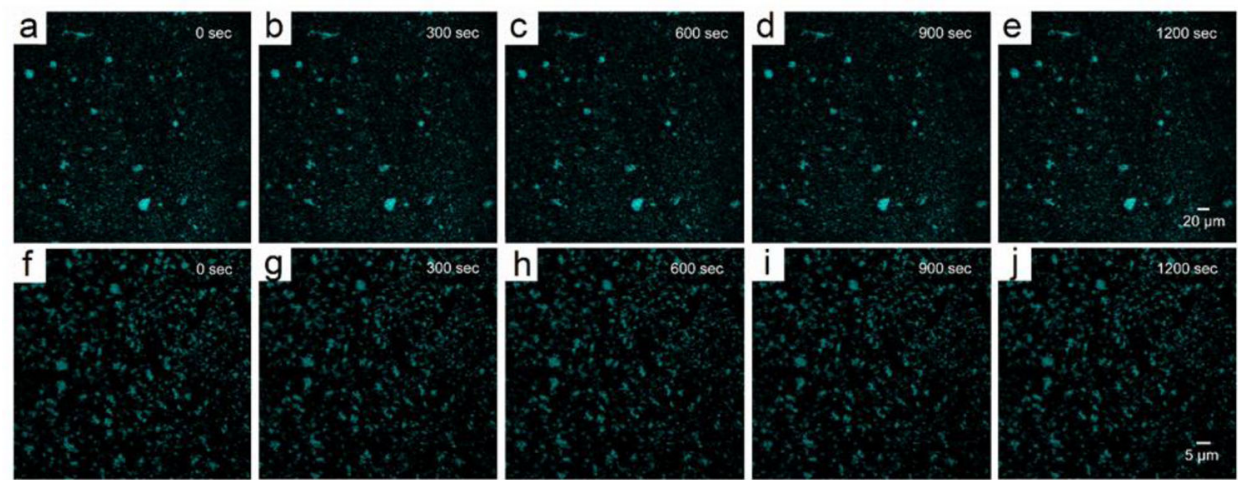

Figure 8.

Times series fluorescent images of the $\mathrm{nZnO}$ over a 20 -minute period. The NPs were subjected to 20 minutes of laser exposure and no apparent decrease in fluorescence intensity was noted, demonstrating their resistance to photobleaching. Like quantum dots, the fluorescence stems from the physical properties of the NPs and is proposed to stem from transitions between energy levels due to the defect present in the samples. 

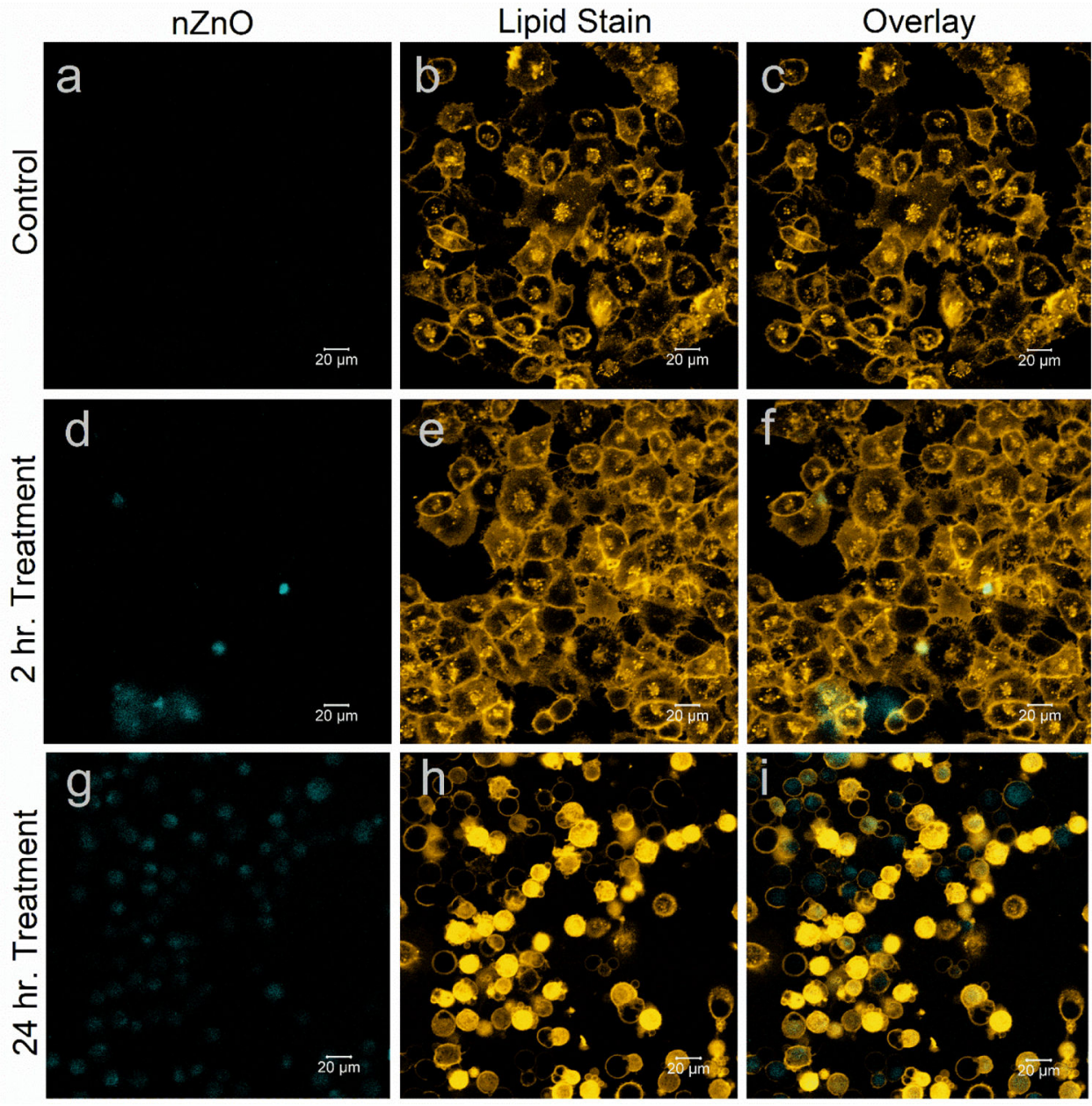

Figure 9.

Confocal images (optical plane thickness $=0.6 \mu \mathrm{m}$ ) of T47D (breast cancer) cells stained with CellMask Orange. The top row (a-c) depicts untreated T47D cells to assess any autofluorescence generated using the same laser settings in the $405 \mathrm{~nm}$ laser channel. The second row (d-f) depicts the T47D cells after 2 hours of $\mathrm{nZnO}$ treatment. Little to no change in cell morphology is noted. The bottom row (g-i) depicts T47D cells after 24 hours $\mathrm{nZnO}$ treatment. The cellular morphology is drastically changed, many blebs are noted, and essentially all NPs that are detectable appear to have been internalized. 